\title{
John Henryism and blood pressure among Nigerian civil servants
}

\author{
Nina Markovic, Clareann H Bunker, Flora A M Ukoli, Lewis H Kuller
}

\begin{abstract}
Study objective-Among urban Nigerian civil servants, higher socioeconomic status is related to increased blood pressure. In the United States, the relation between increased blood pressure and low socioeconomic status or low level of education has been found to be potentiated by high effort active coping (John Henryism) among African-Americans. Thus, the potentiating effect of high effort active coping as measured by the John Henryism Active Coping Scale, on socioeconomic status, as measured by job grade, was considered in relation to blood pressure in a Nigerian civil servant population.

Design-The influence of John Henryism on the association between educational level or socioeconomic status and increased blood pressure was examined during a comprehensive blood pressure survey. John Henryism refers to a strong behavioural predisposition to actively cope with psychosocial environmental stressors.

Setting-Benin City, Nigeria.
\end{abstract}

Participants-Nigerian civil servant sample of 658 adults, aged 20 to 65 years.

Main results-Among those with high John Henryism scores of upper socioeconomic status, whether measured by education level or job grade, there was a trend toward higher systolic and diastolic blood pressures, adjusted for age and body mass index, in men and women, though not statistically significant.

Conclusions-This trend is consistent with recent findings of increased blood pressure among women and AfricanAmericans with high John Henryism and high status jobs.

(F Epidemiol Community Health 1998;52:186-190)

Increased blood pressure has been seen to be associated with a number of physical, sociodemographic, and psychological factors. ${ }^{1-5} \mathrm{Nu}-$ merous epidemiological studies have found socioeconomic status to be inversely related to increased blood pressure among populations in European countries and the United States. ${ }^{6-8}$ Among African-Americans residing in the United States, the relation is thought to be influenced, in part, by a coping strategy called "John Henryism". John Henryism has been defined as a strong behavioural predisposition to cope in an active, determined, and hardworking manner with the stressors of everyday life. ${ }^{9}$ The influence is such that among
African-Americans of low socioeconomic status or of low educational attainment, those with high John Henryism scores show increased blood pressure or increased prevalence of hypertension. ${ }^{9-12}$ This finding has also been confirmed in a white Dutch population. ${ }^{13}$ More recently, high John Henryism has also been found to potentiate an association between high job status and blood pressure among women and African-Americans employed in the United States. ${ }^{14}$ However, the combination of high John Henryism and low education was not associated with increased blood pressure in a young cohort (18-30 year olds)..$^{15}$

Among civil servants in Nigeria, we have observed a positive association between blood pressure and socioeconomic status, with increased blood pressure measurements among those of higher staff status. ${ }^{16}$ During our most recent comprehensive blood pressure survey of civil servants in Benin City, Nigeria, we used the John Henryism Active Coping Scale ${ }^{17}$ to examine its application in this non-Westernised population. We wanted to replicate the analyses of James et $a l,{ }^{9-12}$ that is, to test the hypothesis that those with lesser material coping resources (for example, lower educational attainment, lower job grade) who scored high on the John Henryism Active Coping Scale, would have increased blood pressure. Alternatively, we sought to examine whether or not this measure of active coping further explained our previous finding of increased blood pressure among those of higher staff status.

\section{Methods}

We recruited $84 \%$ of the civil servants at three ministries of Edo State in Benin City, Nigeria, for participation in a comprehensive blood pressure survey. This population has been previously described ${ }^{18}$ and is characterised as a lean population with a low protein and fat intake, moderate sodium intake, and a very low rate of smoking. These analyses are restricted to the $658(81.3 \%)$ of the 809 civil servants, between the ages of 20 and 65 years, who completed the John Henryism Active Coping Scale. Administration of the John Henryism Active Coping Scale was begun after the start of study data collection, thus the first 151 participants did not complete the John Henryism Active Coping Scale. Each individual was seen at three morning appointments scheduled over one week at the study site located in each of the respective ministries. At each of the three visits, three blood pressure determinations were made by Nigerian study team members, certified by a standard protocol. ${ }^{19}$ First and fifth Korotoff sounds were recorded as systolic and 
Table 1 Mean systolic (SBP) and diastolic blood pressure $(D B P)^{\star}$ for the four education-fohn Henryism (fH) groups by sex, Benin City Nigeria Civil Servants 1992

\begin{tabular}{|c|c|c|c|c|c|c|}
\hline & \multicolumn{3}{|l|}{ Men } & \multicolumn{3}{|l|}{ Women } \\
\hline & Number & $S B P$ & $D B P$ & Number & $S B P$ & $D B P$ \\
\hline \multicolumn{7}{|l|}{ High education: } \\
\hline High JH & 74 & 122.4 & 78.3 & 47 & 115.8 & 73.7 \\
\hline Low JH & 63 & 119.2 & 77.7 & 32 & 110.1 & 72.7 \\
\hline \multicolumn{7}{|l|}{ Low education: } \\
\hline High JH & 140 & 121.6 & 77.5 & 92 & 113.6 & 71.7 \\
\hline Low JH & 126 & 118.1 & 75.4 & 84 & 111.3 & 72.0 \\
\hline Entire sample & 403 & 120.3 & 77.0 & 255 & 112.8 & 72.3 \\
\hline \multicolumn{7}{|l|}{ ANOVA p values: } \\
\hline Education & & 0.76 & 0.74 & & 0.71 & 0.65 \\
\hline John Henryism & & 0.10 & 0.26 & & 0.04 & 0.82 \\
\hline Education $\times \mathrm{JH}$ & & 0.73 & 0.36 & & 0.26 & 0.46 \\
\hline \multicolumn{7}{|l|}{ Post hoc ANOVA: } \\
\hline $\begin{array}{l}\text { Between high } \mathrm{JH} \text { and high education } \\
\text { versus all others combined }\end{array}$ & & $\mathrm{p}=0.75$ & $\mathrm{p}=0.88$ & & $\mathrm{p}=0.20$ & $\mathrm{p}=0.39$ \\
\hline
\end{tabular}

* Mean systolic and diastolic blood pressures are an average of six readings across three visits, adjusted for age and body mass index.

diastolic blood pressure respectively. Mean blood pressures calculated as the average of the second and third determinations made at each of the three study visits were used in all presented analyses.

Demographic data were collected at the first visit, and included recording of level of education attained, job grade, marital status, ethnic tribe, height, and weight (in light clothing without shoes). Education was categorised from no education, completion of primary education, completion of secondary education, completion of technical education, to completion of a university degree. Nigerian civil servant job grades are ranked from 1 to 16 , such that grades 1 to 6 are considered Junior staff (unskilled workers, semi-skilled workers, and entry level administrators), while those of grades 7 to 16 are considered Senior staff (highly skilled workers and administrators). Marital status was recorded as never married, married, divorced, and widowed. Ethnic tribal affiliation was self reported. Body mass index was calculated as $\mathrm{kg} / \mathrm{m}^{2}$.

Before administration the John Henryism Active Coping Scale was translated into pidgin English, which is the common language for this population. Back translation by another Nigerian study team member who was unfamiliar with the John Henryism Active Coping Scale was acceptable, and the John Henryism Active Coping Scale was completed by interview to avoid potential bias between literate and illiterate respondents.

Data were analysed by use of the statistical package SPSS-PC+ (SPSS-PC+ Inc, Chicago, IL). Correlations between John Henryism and age, job grade level, and education level were conducted. The $\chi^{2}$ test for differences in John Henryism between men and women, senior staff and junior staff, marital status, and ethnic tribes was also conducted. Contrast groups were compared using analysis of variance (ANOVA). The mean systolic and diastolic blood pressures were adjusted for age and body mass index in the analysis, and sex specific data were analysed.

For analyses of blood pressure outcomes, contrast groups were established according to the methodologies of James and coworkers..$^{9-11} 13$ In the first presented analysis, four contrast groups were constructed for assessing education and John Henryism, based on the median splits of the John Henryism Active Coping Scale and educational attainment of the sample. ${ }^{9}$ For the second presented analysis, four contrast groups were constructed based upon the median splits of the John Henryism Active Coping Scale score and job grade status (Junior or Senior $)^{16}$ for the analysis of staff status and John Henryism.

\section{Results}

The John Henryism Active Coping Scale scores among these Nigerian civil servants ranged from 22 to 60 , with a highly skewed distribution to the higher end of the scale. The median John Henryism Active Coping Scale score in this population was 57 , with 16.8 per cent of the respondents scoring 60 . The John Henryism score mean and standard deviation were 55.9 and 4.14. The median for education was completion of secondary level education, so that those who had completed technical school beyond secondary school or university were grouped as "high" education.

John Henryism Active Coping Scale scores did not differ significantly between men and women (mean scores of 55.8 and 56.1 respectively), nor were there significant differences between women and men in the proportion classified as "high John Henryism" (per cent classified as high John Henryism among men was 78.7 and among women 80.4 ). No significant correlations were noted between John Henryism scores and age $(r=0.0002, \mathrm{p}>0.05)$, body mass index $(r=0.038, \mathrm{p}>0.05)$, job grade level $(r=0.011, \mathrm{p}>0.05)$, or level of formal education $(r=0.028, p>0.05)$. No significant differences were identified among marital status categories or among the ethnic tribes.

Mean systolic and diastolic blood pressures were positively associated with levels of education ( $r=0.03, r=0.06$ respectively) and staff level ( $r=0.18, \quad r=0.19$ respectively), age $(r=0.04, r=0.28$ respectively) and body mass index $(r=0.16, r=0.19$, respectively). These correlations were all significant at $\mathrm{p}<0.001$ except for level of education. In univariate analyses of known risk factors, age, body mass index, waist to hip ratio, number of years urban living, number of children, and blood glucose concentration were significantly associated with blood pressure among the entire population. However, only age, body mass index, and job grade remained significant $(p<0.05)$ in the linear regression models for blood pressures. Because job grade was used in the John Henryism construct, only age and body mass index were adjusted for in analysis of differences between the John Henryism contrast groups. Men demonstrated significantly higher systolic and diastolic blood pressures, and sex specific data are presented for analysis of differences between John Henryism contrast groups (mean systolic and diastolic blood pressures among men was $120 / 77 \mathrm{~mm} \mathrm{Hg}$; and among women 113/72 mm Hg, $\mathrm{p}<0.01$ ).

Among the men, adjusted mean systolic and diastolic blood pressures were higher in Senior staff than in Junior staff $(123.6 \mathrm{~mm} \mathrm{Hg} / 79.2$ 
Table 2 Mean systolic (SBP) and diastolic blood pressure (DBP)* for the staff status-fohn Henryism (FH) groups by sex, Benin City Nigeria Civil Servants 1992

\begin{tabular}{|c|c|c|c|c|c|c|}
\hline & \multicolumn{3}{|l|}{ Men } & \multicolumn{3}{|l|}{ Women } \\
\hline & Number & $S B P$ & $D B P$ & Number & $S B P$ & $D B P$ \\
\hline \multicolumn{7}{|l|}{ Senior staff: } \\
\hline High JH & 97 & 125.8 & 79.7 & 62 & 115.1 & 73.3 \\
\hline Low JH & 79 & 119.0 & 77.2 & 48 & 111.5 & 73.2 \\
\hline \multicolumn{7}{|l|}{ Junior staff: } \\
\hline High JH & 117 & 118.6 & 76.2 & 77 & 113.8 & 71.7 \\
\hline Low JH & 110 & 118.0 & 75.4 & 68 & 110.6 & 71.5 \\
\hline Entire sample & 403 & 120.3 & 77.0 & 255 & 112.8 & 72.3 \\
\hline \multicolumn{7}{|l|}{ ANOVA p values: } \\
\hline Staff status & & 0.26 & 0.23 & & 0.19 & 0.76 \\
\hline John Henryism & & 0.11 & 0.27 & & 0.04 & 0.79 \\
\hline Staff status $\times \mathrm{JH}$ & & 0.26 & 0.84 & & 0.59 & 0.55 \\
\hline \multicolumn{7}{|l|}{ Post hoc ANOVA: } \\
\hline $\begin{array}{l}\text { Between high } \mathrm{JH} \text { and senior staff } \\
\text { versus all others combined }\end{array}$ & & $\mathrm{p}=0.03$ & $\mathrm{p}=0.15$ & & $\mathrm{p}=0.96$ & $\mathrm{p}=0.69$ \\
\hline
\end{tabular}

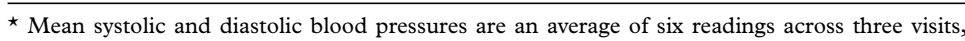
adjusted for age and body mass index.

$\mathrm{mm} \mathrm{Hg}$ versus $117.8 \mathrm{~mm} \mathrm{Hg} / 75.5 \mathrm{~mm} \mathrm{Hg}$, respectively, $\mathrm{p}<0.05)$. Significant differences in adjusted blood pressures were not observed between women of Senior and Junior staff status, nor between high and low education contrast groups in either sex. Table 1 shows the comparison of adjusted mean systolic and diastolic blood pressure in high/low John Henryism groups across high/low education groups. Differences across the four John Henryism education groups in men were small and not significant. Among women, systolic blood pressure was higher in both high John Henryism groups $(p=0.04)$, and was highest in the high education group.

When examined in relation to staff status (table 2) high John Henryism had no influence on blood pressure among the men of Junior staff status. However, among the men of Senior staff status, higher blood pressure was observed among the high John Henryism group, while the low John Henryism group had mean blood pressures similar to the men of Junior staff status. Among women, systolic blood pressure was higher in both high John Henryism groups $(p=0.04)$ and was highest among the Senior staff. Of note, the Senior staff in the high John Henryism group had the highest blood pressure among both men and women. Although the formal ANOVA test for interaction between staff and John Henryism status was not significant, post hoc analyses of adjusted blood pressure was significantly higher in the high John Henryism/Senior male staff compared with the other three contrast groups combined (high John Henryism/Senior male staff $125.8 \mathrm{~mm}$ $\mathrm{Hg} / 79.7 \mathrm{~mm} \mathrm{Hg}$ versus $118.5 \mathrm{~mm} \mathrm{Hg} / 76.2$ $\mathrm{mm} \mathrm{Hg}$ all other men, $\mathrm{p}=0.03$ systolic, $\mathrm{p}=0.15$ diastolic). Among women, those catorgorised as high John Henryism/Senior staff status did not have significantly higher systolic or diastolic blood pressures compared with the other three contrast groups combined (high John Henryism/Senior female staff $115.1 \mathrm{~mm} \mathrm{Hg} /$ $73.3 \mathrm{~mm} \mathrm{Hg}$ versus $112.1 \mathrm{~mm} \mathrm{Hg} / 72.0 \mathrm{~mm}$ $\mathrm{Hg}$ all other women, $\mathrm{p}=0.96$ systolic, $\mathrm{p}=0.69$ diastolic). Staff status was no longer significantly related to blood pressure after the inclusion of John Henryism in the analyses.

\section{Discussion}

In accordance with our previous study of Nigerian civil servants, we noted higher systolic and diastolic blood pressures among the upper socioeconomic status group, as categorised by civil servant job grades. This is in contrast with findings in US and European populations where there is an inverse relation between blood pressure and socioeconomic status. In this Nigerian population, we observed a non-significant trend toward increased blood pressures with higher education level, and with higher staff status, among those with higher John Henryism. This finding is consistent with the hypothesis that high effort coping among those of higher job status may result in blood pressure increases among Nigerian civil servants. In post hoc analyses, significantly higher systolic blood pressure was observed among Senior male staff with high John Henryism compared with all other men. Those with lesser coping resources, such as lower educational attainment, or lower job grade, and high John Henryism did not demonstrate significantly increased systolic or diastolic blood pressure.

In earlier studies of US black populations, ${ }^{9-11}$ it was the lower socioeconomic status stratum that had the higher blood pressure, and blood pressure was even higher among those of both lower socioeconomic status and high John Henryism. It was hypothesised that blood pressure was affected by stresses resulting from high coping efforts among those with very limited resources for coping. However, the findings in this study are consistent with a more recent study ${ }^{14}$ that found higher blood pressure among women and among black men of higher occupational status and high John Henryism. These groups should have relatively high coping resources suggesting that the effects of John Henryism are not dependent on limited coping resources. Light and colleagues found high blood pressure among women and among black men of higher occupational status and high John Henryism, and suggested that the stress of breaking down traditional barriers for occupational advancement among women and African-Americans in the United States may interact with John Henryism and the association with increased blood pressure measurements. ${ }^{14}$ This leads to an alternative hypothesis that John Henryism interacts with other factors predisposing to higher blood pressure, whether the stresses of low socioeconomic status or the stress of breaking down traditional barriers to occupational advancement or other unidentified stresses and risk factors.

We speculate that several factors may have influenced the significance of our findings. Firstly, although the literal translation of the John Henryism Active Coping Scale was acceptable, the contextual interpretation may not have been adequate in identifying those with an excessive determination or drive to actively cope with behavioural stressors in the environment. In this economically developing country where many lack material coping resources, Nigerians struggle against enormous odds daily to accomplish what may be consid- 
ered simple everyday task, such as obtaining water. Thus, active coping with stressors in the environment - that is, John Henryism-is a way of routine life for all levels of socioeconomic status in Nigeria.

Additionally, this Nigerian civil servant population is considered reflective of a society in transition to a more "westernised" lifestyle. It is unclear whether a cultural tradition of highly active coping or if high levels of coping are required to accompany the social change leading to westernisation is reflected in our finding of high John Henryism among the entire spectrum of civil servants. These analyses are based upon cross sectional data, and it is unclear where in the continuum of the changing gradient between socioeconomic status and cardiovascular disease risk these Nigerian civil servants occupy. It may be that this population in early westernisation reflect a midpoint in the continuum, and the population is experiencing high levels of coping during this period of transition. As the association between socioeconomic status and cardiovascular disease risk becomes indirect, measures of John Henryism will reflect personal intrinsic characteristics rather than reflect a response to social changes.

Secondly, in our study sample of civil servants, the low end of socioeconomic status and educational attaintment levels in Nigerian society - that is, the unemployed and village farmers - were not surveyed. Without those of the lowest end of material coping resources, we may have lacked the contrast necessary to observe an association. This is similar to James and coworkers findings in American whites. ${ }^{10}$

Thirdly, by administering the John Henryism Active Coping Scale through interview, scores may have been inflated as a result of the social saliency of the more positive responses. This is reflected in the large percentage of the sample that scored 60 , and the high median score of 57. Studies using the John Henryism Active Coping Scale conducted in the United States and the Netherlands also report highly skewed distributions with median scores of 54. ${ }^{91013}$

Finally, it may be that those classified as low socioeconomic status in this civil servant population represent those who have more adequate coping resources compared with their similarly educated peers who face very high unemployment rates. Thus, a secure civil servant job among those of lower socioeconomic status may attenuate stressors, resulting in lowered sympathetic arousal and a lower risk for hypertension, as demonstrated by the lower mean systolic and diastolic blood pressures in the low socioeconomic status group. However, among the upper socioeconomic status, higher blood pressures may be attributed in part to stress caused by increased responsibilities in providing support to extended family members and maintaining an observable upper socioeconomic status lifestyle. This may explain the finding of highest blood pressures among those of high John Henryism and upper socioeconomic status level. In this regard, other measures of sociodemographic related stres-
KEY POINTS

- Previously reported findings of increased blood pressure among Nigerian senior staff are not wholly explained by body mass index and age.

- In west African urban civil servants of upper socioeconomic status, with high scores on the John Henry Active Coping Scale, there was a trend towards higher blood pressures adjusted for age and body mass index.

- This trend is consistent with recent findings of increased blood pressure among women and African-Americans with high John Henryism and high status jobs.

sors, such as Dressler's "lifestyle incongruity"20 are being explored among this population.

The protocol used to measure blood pressure in this survey is not considered to have contributed to the observed blood pressure differences among the staff status, educational level, or John Henryism contrast groups. The possibility of blood pressure measurement as being a novel experience, reflected in an increased blood pressure (a "white coat" response) has been considered. Previous analyses of blood pressure determinations conducted among this population did not show any significant variability among the staff status groupings nor sex in the repeated blood pressure measurements ${ }^{21}$ that would affect these results. Indeed, we do not find evidence that repeated blood pressure determination variability is greater among these urban dwelling Nigerian civil servants compared with other populations in either developed or developing countries.

In conclusion, we noted a consistent trend of higher blood pressures for those of high John Henryism and high education or staff status in this Nigerian civil servant population. Further research of the John Henryism Active Coping Scale among all social strata in economically developing countries is suggested to determine its application in such populations.

We gratefully acknowledge the cooperation of the Edo State of Nigeria Ministries of Education, Information, and Agriculture. The authors also thank the manuscript referees for their comments, which enhanced the quality of this manuscript.

Funding: this research was supported by Research Grant HL44413 (US National Institutes of Health) and Training Grant HL07011 (USNational Institutes of Health)

Conflicts of interest: none.

1 Stamler J, Rhomberg P, Schoenberger JA, et al. Multivariate analysis of the relationship of seven variables to blood pres-
sure: findings of the Chicago Heart Association Detection Project in Industry, 1967-1972. F Chron Dis 1995;28:52748.

2 Cottington EM, Brock BM, Mouse JS, Hawthorn VM. Psychosocial factors and blood pressure in the Michigan statewide blood pressure survey. Am f Epidemiol 1985;121: 515-29.

3 James SA. Psychosocial precursors of hypertension: a review of the epidemiologic evidence. Circulation 1987;76 (suppl 1): $160-6$.

4 Anderson NB, McNeilly M, Myers J. Autonomic reactivity and hypertension in blacks: a review and proposed model. Ethn Dis 1991;1:154-70.

5 Calhoun DA. Hypertension in blacks: socioeconomic stress and sympathetic nervous system activity. Am f Med Sci 1992;304:306-11. 
6 Syme SL, Oakes TW, Friedman GD. Social class and racial differences in blood pressure. Am $\mathcal{f}$ Public Health 1974;4:619-23.

7 Marmot MG, Kogevians M, Elston MA. Social/economic status and disease. Annu Rev Public Health 1987;8:111-37.

8 Hypertension Detection and Follow-up Program Cooperative Group. Race, education and prevalence of hypertension. Am f Epidemiol 1977;106:351-61

9 James SA, Hartnett SA, Kalsbeek WD. John Henryismism and blood pressure differences among black men. F Behav Med 1983;6:259-77.

10 James SA, Strogatz DS, Wing SB, Ramsey DL. Socioeconomic status, John Henryism, and hypertension in blacks and whites. Am 7 Epidemiol 1987;126:664-73.

11 James SA, Keenan NL, Strogatz DS, Browing SR, Garrett JM. Socioeconomic status, John Henryism, and blood pressure in black adults. The Pitt County Study. Am 7 Epipressure in black adults.
demiol 1992;135:59-67.

12 James SA. John Henryism and the health of AfricanJames SA. John Henryism and the health of

13 Duijkers TJ, Drijver M, Kromhout D, James SA "John Henryism" and blood pressure in a Dutch population. Psychosom Med 1988;50:353-9.

14 Light KC, Brownley DA, Turner R, et al. Job status and high-effort coping influence work blood pressure in women and blacks. Hypertension 1995;25 (part 1):554-9.
15 McKetney EC, Ragland DR. John Henryism, education, and blood pressure in young adults. The CARDIA Study. Am f Epidemiol 1996;143:787-91.

16 Bunker CH, Ukoli FAM, Nwankwo MU, et al. Factors associated with hypertension in Nigerian civil servants. Prev Med 1992;21:710-22.

17 Weinrich SP, Weinrich MC, Keil JE, Gazes PD, Potter E. The John Henryism and Framingham Type A Scales. Measurement properties in elderly blacks and whites. Am $\mathcal{F}$ Epidemiol 1988;128:165-78.

18 Bunker CH, Ukoli FA, Matthews KA, Kriska AM, Huston SL, Kuller LH. Weight threshold and blood pressure in a lean black population. Hypertension 1995;26:616-23.

19 Dischinger P, DuChene AG. Quality control aspects of blood pressure measurements in the Multiple Risk Factor Intervention Trial. Control Clin Trials 1986;7 (suppl):137$57 \mathrm{~S}$.

20 Dressler WW. Social class, skin color, and arterial blood pressure in two societies. Ethn Dis 1991;1:60-77.

21 Markovic N, Olomu IN, Bunker CH, Huston SL, Ukoli FAM, Kuller LH. Adequacy of a single visit for classification of hypertensive status in a Nigerian civil servant population. Int f Epidemiol 1994;23:723-9. 